\title{
Lubrication Performance of Different Concentrations of Al203 Nanofluids on Minimum Quantity Lubrication Milling
}

\section{Xiufang Bai}

Qingdao Binhai University

Juan Jiang

Qingdao Binhai University

C. H. Li (D sy_lichanghe@163.com)

Qingdao University of Technology https://orcid.org/0000-0003-4409-956X

\section{Lan Dong}

Qingdao Binhai University

\section{Zhenjing Duan}

Qingdao University of Technology

Haiying Zhang

Qingdao Binhai University

\section{Research Article}

Keywords: Milling, Al2O3 nanofluid, Minimum Quantity Lubrication(MQL), Surface Micromorphology

Posted Date: February 24th, 2021

DOl: https://doi.org/10.21203/rs.3.rs-230176/v1

License: (c) (i) This work is licensed under a Creative Commons Attribution 4.0 International License. Read Full License 


\title{
Lubrication Performance of Different Concentrations of $\mathrm{Al}_{2} \mathrm{O}_{3}$
}

\author{
Nanofluids on Minimum Quantity Lubrication Milling \\ Xiufang Bai ${ }^{1,2}$,Juan Jiang ${ }^{1,2}$,Changhe $\mathrm{Li}^{3, *}$, Lan Dong ${ }^{1,2, *}$, Zhenjing Duan $^{3}$,Haiying \\ 1 Engineering and Technology R\&D center of Mechanical and Electrical in Colleges of Shandong, Qingdao Binhai University, Qingdao, China, \\ 266555 \\ 2 School of Mechanical and Electrical Engineering, Qingdao Binhai University, Qingdao, China, \\ 266555 \\ 3 School of Mechanical and Automotive Engineering, Qingdao University of Technology, Qingdao, China,
266520
}

*Corresponding author. School of Mechanical and Automotive Engineering, Qingdao University of

Technology, 266520 Qingdao, China

Tel: +86-532-68052760; Fax: +86-532-85071286

E-mail address: sy_lichanghe@163.com (Changhe Li)

Engineering and Technology R\&D center of Mechanical and Electrical in Colleges of Shandong,

Qingdao Binhai University, 266555 Qingdao, China

School of Mechanical and Electrical Engineering, Qingdao Binhai University, 266555 Qingdao, China

Tel: +86-532-83150312; Fax: +86-532-83150312

E-mail address: 804203464@qq.com(Lan Dong)

Authorships: Xiufang Bai: Engineering and Technology R\&D center of Mechanical and Electrical in Colleges of

Shandong,

Qingdao Binhai University, 266555 Qingdao, China

School of Mechanical and Electrical Engineering, Qingdao Binhai University, 266555 Qingdao, China

E-mail address:bxf1979@126.com

Juan Jiang:Engineering and Technology R\&D center of Mechanical and Electrical in Colleges of Shandong,

Qingdao Binhai University, 266555 Qingdao, China

School of Mechanical and Electrical Engineering, Qingdao Binhai University, 266555 Qingdao, China

E-mail address:413544450@qq.com

Changhe Li: School of Mechanical and Automotive Engineering, Qingdao University of Technology, 266520

Qingdao, China

E-mail address: sy_lichanghe@163.com

Lan Dong: Engineering and Technology R\&D center of Mechanical and Electrical in Colleges of Shandong,

Qingdao Binhai University, 266555 Qingdao, China

School of Mechanical and Electrical Engineering, Qingdao Binhai University, 266555 Qingdao, China

E-mail address:804203464@qq.com

Zhenjing Duan: School of Mechanical and Automotive Engineering, Qingdao University of Technology, 266520

$$
\text { Qingdao, China }
$$

E-mail address: zhenjing456@qq.com

Haiying Zhang:Engineering and Technology R\&D center of Mechanical and Electrical in Colleges of Shandong,

Qingdao Binhai University, 266555 Qingdao, China

School of Mechanical and Electrical Engineering, Qingdao Binhai University, 266555 Qingdao, China

E-mail address:64029205@qq.com

Abstract: Lubricant plays an important role in machining. Due to the problems of environmental protection and workers' health, traditional lubricants are gradually replaced. Nanofluid, adding 
nanoparticles into base oil, is a kind of environment-friendly low-carbon lubricant, which improves not only the heat transfer capacity but also the lubrication performance. However, how many nanoparticles added into the fluid can improve the lubrication performance best? There are few studies on the mechanism of lubrication performance of different concentrations, and the results are not very clear. In this research, nanofluid as lubricating fluid is made by adding $0.5^{\sim} 2.0 \%$ mass concentration of $\mathrm{Al}_{2} \mathrm{O}_{3}$ nanoparticles to the cottonseed oil during milling Grade 45 steel in minimum quantity lubrication (MQL) mode. The tribological properties of nanofluids with different concentrations at the tool/workpiece interface were studied by macro evaluation parameters (specific energy) and micro evaluation parameters (surface roughness, micro morphology, contact angle and viscosity ). The results show that the concentration of nanoparticles has the most optimal value. When the concentration is $0.5 \mathrm{wt} \%$, the specific energy is the minimum $(0.281)$, and the roughness value is the lowest $(1.63 \mu \mathrm{m})$. Meanwhile, slender chip and the largest droplet wetting area are obtained, which indicates better tribological properties. There is a nonlinear relationship between the lubricating effect of nanofluid and its concentration. The proper concentration of $\mathrm{Al}_{2} \mathrm{O}_{3}$ nanofluid has good tribological properties and more potential to replace the pouring lubrication.

Keywords: Milling; $\mathrm{Al}_{2} \mathrm{O}_{3}$ nanofluid; Minimum Quantity Lubrication(MQL); Surface Micromorphology

\section{Introduction}

Milling, due to high material removal rate and good surface quality of the processed workpiece, is one of the most important processing methods and has been widely used in the mold processing, automobile manufacturing, aerospace, and other industries. In the milling processing, the friction, high temperature and high pressure in the cutting area will cause surface thermal damage, reduce the wear resistance, fatigue and service life of mechanical parts. Therefore, lubrication and cooling are very important in the milling area[1-3]. Conventionally, a large amount of cutting fluid is usually poured into the zone area to remove the generated heat and reduce the wear during machining. However, extensive use of cutting fluid will greatly increase production costs [4]. Moreover, cutting fluid not only causes serious 
pollution to the environment, but also harms human health [5]. In the requirement of sustainable development, milling must comply with the development trend of the times and meet the need of green development[6-8].

Minimum quantity lubrication(MQL) technology is a green processing one developed in recent years[9]. After the high-pressure gas is mixed with a small amount of cutting fluid, micro droplets are formed and sprayed into the machining area. The high-pressure air flow plays the role of cooling and chip removal[10], and the cutting fluid adheres to the machining surface of the workpiece, thus forms a protective film to act as an effect of lubrication.The fluid based on vegetable oil is becoming more and more popular owing to its non-toxicity [11,12], good biodegradability [13], high flash point [14], renewability and affordability [15] .Many scholars have carried out a lot of relevant experimental studies using vegetable oil as base oil.

Wang et al. [16] studied the lubrication properties of seven types of vegetable oils using MQL and found that vegetable oil obtained better lubrication properties than mineral oil. Li et al.[17,18] investigated the lubrication performances of seven types of vegetables oil including castor, soybean, rapeseed, corn, sunflower, peanut, and palm oils, and revealed that palm oil is the optimum base oil of MQL grinding. Cetin et al. [19] evaluated the performance with two vegetable-based cutting fluids and two commercial types of cutting fluids and investigated that two vegetable-based cutting fluids obtained better performance than commercial cutting fluids. Pervaiz et al. [20] mixed a vegetable oil-based MQL system with sub-zero temperature air, and the results indicated that vegetable oil-based cooling strategy had promising potential to replace conventional flood cooling methods. Bai et al[21] experimentally evaluated the lubrication performance of five types of vegetable oil in comparison with synthetic cutting fluid in milling Grade 45 steel. The result showed vegetable-based oil obtained more superior surface quality than the synthetic cutting fluid.

Pure vegetable oil-based cutting fluid is not effective when large quantity of heat is generated at the tool-workpiece interface, while nanofluid MQL not only 
maintains all the advantages of MQL but also solves the fatal defects caused by the heat transfer due to the powerful heat transfer capability of nanoparticles[22-24]. A quantity of research has been conducted to check the lubrication and cooling properties of nanofluid by the researchers at home and abroad.

Zhang et al. $[25,26]$ explored the lubricating property of four types of grinding working conditions (namely dry, flood, MQL and nanofluid MQL), and the results indicated that nanofluid MQL produced the best lubricating property. Luo et al. [27] studied the lubricating properties of $\mathrm{Al}_{2} \mathrm{O}_{3}$ nanoparticles and discovered that the friction coefficient and the wear scar diameter were the smallest when the concentration was $0.1 \mathrm{wt} \%$. Setti et al. [28] investigated the lubrication properties of water based $\mathrm{CuO}$ and $\mathrm{Al}_{2} \mathrm{O}_{3}$. Application of nanofluid lead to the reduction of forces and temperature, and improved the grindability of Ti-6Al-4V. Mao et al. [29] carried grinding experiments under four different lubrication conditions (namely dry, flood, pure MQL, and water based $\mathrm{Al}_{2} \mathrm{O}_{3}$ nanofluid $\mathrm{MQL}$ ), and found that nanofluid $\mathrm{MQL}$ grinding had a better lubrication condition in comparison to pure water MQL grinding. Li et al. [30] investigated the cooling and lubrication performances adding graphene nanoparticles into vegetable oil, and found that it was effective to improve the milling characteristics. Hadi et al. [31] studied the effects of $\mathrm{Al}_{2} \mathrm{O}_{3}$ nanoparticles when milling AISI D3 steel. The results showed that the surface roughness decreased in comparison to pure MQL. Bai et al[32],Dong et al[33] Yin et al [34] investigated lubrication performances under four conditions including dry, flood, MQL, and $\mathrm{Al}_{2} \mathrm{O}_{3}$ nanofluid MQL milling 45 steel. The results revealed that $\mathrm{Al}_{2} \mathrm{O}_{3}$ nanofluid MQL had the lowest force and friction coefficient. Gao et al[35] investigated the influences of surfactant type and dispersing mechanism on the dispersion effect of palm oil-based CNT nanofluids. Results showed that APE-10 was the optimal dispersant of CNT nanofluids. Duan et al[36] studied the influence law of the position parameters (target distance, incidence angle, and elevation angle) of the nozzle on the surface roughness of milling, and obtained the optimal nozzle profile parameters.Wang et al[37] reviewed the current advanced research on NMQL with vegetable oil, and proposed textured tool and ultrasonic vibration-assisted nanofluid turning to 
increase the effective flow rate. Gao et al[38] investigate the Carbon fiber-reinforced polymer (CFRP) grindability of NMQL and concluded that the surface roughness Ra, $\mathrm{Rz}$, and RSm values of CNT NMQL in the feed direction were reduced in comparison to dry grinding.

Different concentrations of nanofluids have different physical and chemical properties. Zhang et al. [39] added $\mathrm{MoS}_{2}, \mathrm{CNTs}$, and $\mathrm{ZrO}_{2}$ nanoparticles in grinding fluid to verify the lubrication effects. The results demonstrated that MoS2 nanoparticles with $2 \%$ achieved satisfactory lucbrication effects. Zhang et al. [40] mixed $\mathrm{Al}_{2} \mathrm{O}_{3}$ and $\mathrm{SiC}$ nanoparticles to investigate the lubrication performances. The results showed that the optimal ratio was achieved under 2:1. Wang et al. [41] added different concentration $\mathrm{Al}_{2} \mathrm{O}_{3}$ nanoparticles into palm oil to investigate the tribological performance of the wheel/workpiece interface in MQL grinding. It was concluded that the optimal nanofluid concentration was 2 vol\%. Rahmati B et al.[42] applied $\mathrm{MoS}_{2}$ nanofluid in milling AL6061-T6 alloy, and concluded that the product quality was enhanced and superior when nanoparticles concentration were 0.5 wt\%.

According to the above research, nanoparticles show very promising application as additives for lubricant to improve the tribological property. Although previous literature already discussed the tribological behavior of $\mathrm{Al}_{2} \mathrm{O}_{3}$ nanofluids in $\mathrm{MQL}$ machining environment, no study was conducted to find the optimum $\mathrm{Al}_{2} \mathrm{O}_{3}$ concentration in cottonseed oil for MQL milling Grade 45 steel, and the mechanism of MQL milling lubrication and the effect of nanoparticle agglomeration on the surface quality of milled workpiece are still unclear. Depending on the previous experimental outcomes[21,32], an experimental endeavor was conducted to check the tribological behavior of the $\mathrm{Al}_{2} \mathrm{O}_{3}$ and cottonseed oil under different concentration of $\mathrm{Al}_{2} \mathrm{O}_{3}$ (ranging from $0.5 \mathrm{wt} \%-2 \mathrm{wt} \%$ ). Through studying the milling force, surface roughness, and micromorphology of the workpiece surface under different concentrations, the lubrication performance of the tool/workpiece interface was experimentally evaluated. It is expected that this research will promote optimum concentration of $\mathrm{Al}_{2} \mathrm{O}_{3}$ nanofluied and its respective tribological characteristics. 


\section{Experiment}

\subsection{Experimental Setup}

The experiment was performed at the machining center of Dema ML1060B with dimensions of $3200 \times 2450 \times 2000 \mathrm{~mm}(\mathrm{~L} \times \mathrm{W} \times \mathrm{H})$. The main technical parameters are described as follows: spindle power of $11 \mathrm{KW}$, maximum speed of $8000 \mathrm{r} / \mathrm{min}$, worktable driving motor power of $5 \mathrm{KW}$, cutting range of $1000 \times 600 \mathrm{~mm}$, and cutting feed rate of $10,000 \mathrm{~mm} / \mathrm{min}$. MQL device $\mathrm{KS}-2106$ was used to convey the lubricant. The milling force was measured by a tridirectional piezoelectric dynamometer JR-YDCL-III 105B. Contact pointer measuring instrument SC6C was used to measure the surface roughness of the workpiece. The surface micromorphology of the workpiece was measured by DV2TLV. Viscometer DV2T was used to measure the viscosity of each nanofluid. The experimental instruments and schematic of the milling experiment are shown in Fig. 1and 2, respectively.

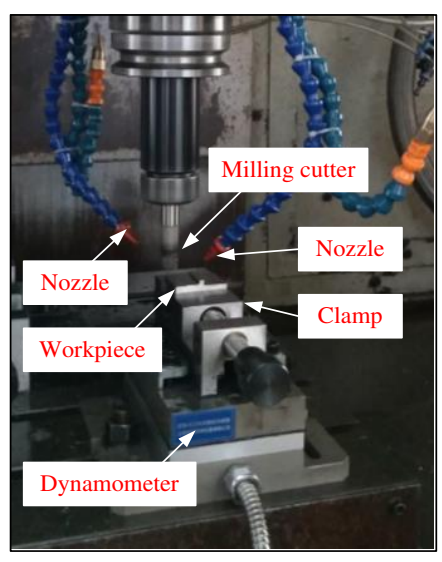

(a)Milling force measuring device

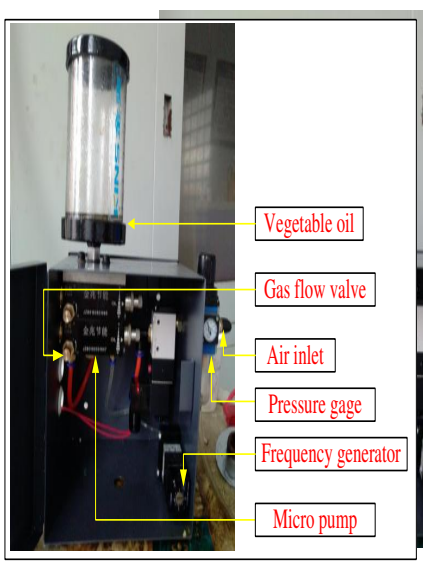

(b)MQL supply system

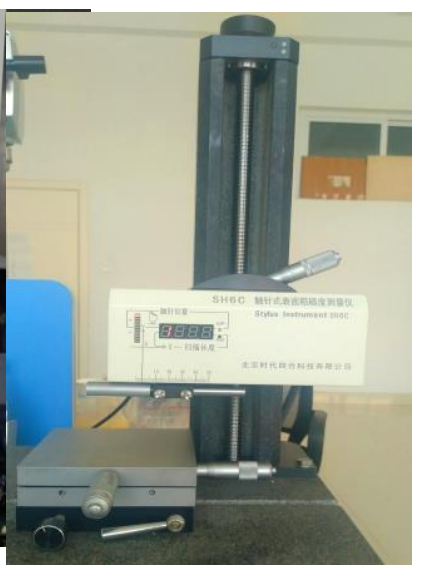

(c)Surface roughness instrument
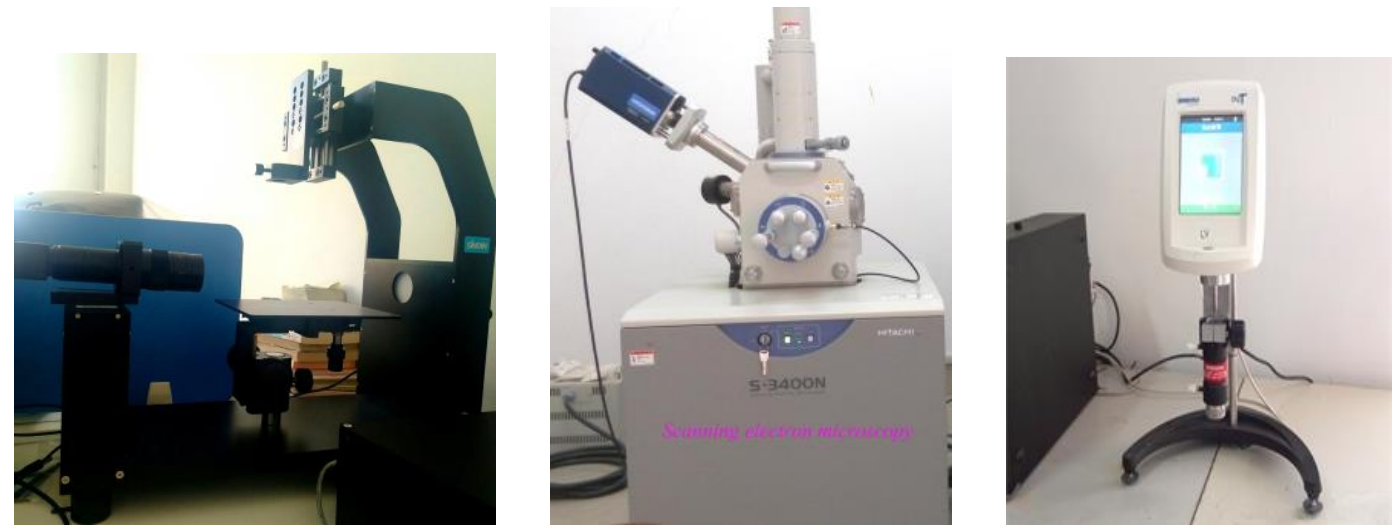

(d) contact angle instrument (e) Scanning electron microscope(SEM) (f) Viscometer 
Fig. 1 Experiment instruments
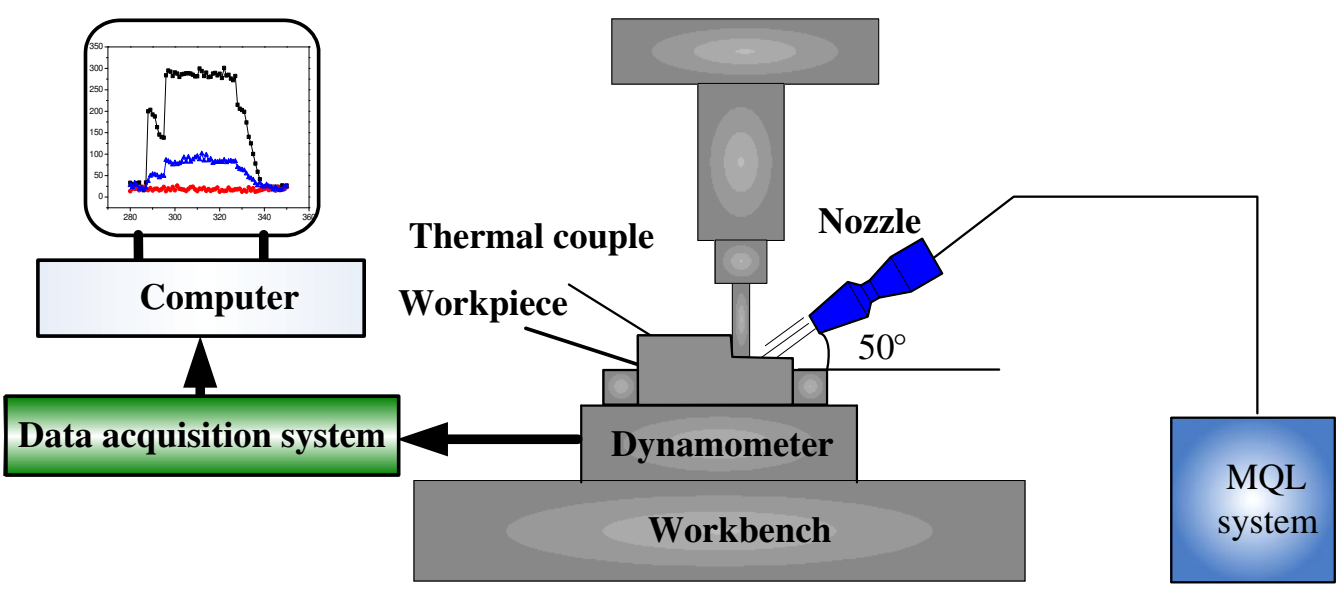

Fig. 2 Schematic of milling experiment

\subsection{Experimental Materials}

Grade 45 steel was ultilized as the workpiece in the experiment, whose size is 40 $\mathrm{mm} \times 30 \mathrm{~mm} \times 30 \mathrm{~mm}(\mathrm{~L} \times \mathrm{W} \times \mathrm{H})$. The chemical composition and mechanical properties of the material are shown in Table 1 and 2 .

Table 1 chemical composition of Grade 45 steel

\begin{tabular}{|c|c|c|c|c|c|c|c|c|}
\hline Element & C & $\mathrm{Si}$ & $\mathrm{Mn}$ & $\mathrm{Cu}$ & $\mathrm{Ni}$ & $\mathrm{Cr}$ & $P$ & $\mathrm{~S}$ \\
\hline Component/ & $0.42 \sim 0.5$ & $0.17 \sim 0.3$ & $0.50 \sim 0.80$ & $\leq 0.2$ & $\leq 0.30$ & $\leq 0.2$ & 0.035 & 0.035 \\
\hline$\%$ & 0 & 7 & $0.50=0.80$ & 5 & $=0.30$ & 5 & & \\
\hline
\end{tabular}

Table 2 Mechanical properties of Grade 45 steel

\begin{tabular}{ccccccc}
\hline $\begin{array}{c}\text { Modulus of } \\
\text { elasticity } \\
(G P a)\end{array}$ & $\begin{array}{c}\text { Poisson's } \\
\text { ratio }\end{array}$ & $\begin{array}{c}\text { Tensile } \\
\text { strength } \\
(\mathrm{MPa})\end{array}$ & $\begin{array}{c}\text { Yield } \\
\text { strength } \\
(\mathrm{MPa})\end{array}$ & $\begin{array}{c}\text { Hardness } \\
(H R C)\end{array}$ & $\begin{array}{c}\text { Elongation( } \\
\%)\end{array}$ & $\begin{array}{c}\text { Density } \\
\rho\left(\mathrm{g} / \mathrm{m}^{3}\right)\end{array}$ \\
\hline 210 & 0.31 & 600 & 355 & $48^{\sim} 55$ & 16 & 7.85 \\
\hline
\end{tabular}

\subsection{Experimental Scheme}

In the experiment, cottonseed oil was used as the base oil and $\mathrm{Al}_{2} \mathrm{O}_{3}$ nanoparticles of different concentrations were added to the base oil to form nanofluids. When the concentration of nanoparticles was 0 , it was pure cottonseed oil, which was used as the reference group. Each group only changed the quantity of $\mathrm{Al}_{2} \mathrm{O}_{3}$ nanoparticle, and other experimental conditions remained unchanged.

Nanofluid is a mixture of base oil and nanoparticles. According to the previous 
experimental study $[21,32]$, compared with castor oil, soybean oil and peanut oil, cottonseed oil and palm oil as base oil with $\mathrm{Al}_{2} \mathrm{O}_{3}$ nanoparticles obtained the best lubrication performance. However, the viscosity of palm oil is bigger than that of cottonseed. When the room temperature is low, it is easy to coagulate in the experiment. Therefore, the cottonseed oil is used as base oil, and $\mathrm{Al}_{2} \mathrm{O}_{3}$ nanoparticles selected as the additives. The physical properties of $\mathrm{Al}_{2} \mathrm{O}_{3}$ nanoparticles are listed in Table 3. The literature[43] investigated that even adding a small amount of nanoparticles could significantly improve the lubrication performance. However, the performance of the nanoparticles was nonlinear with its concentration. In the experiments, the tribological performances at the tool/workpiece interface were studied with the use of different mass concentration $(0 \%, 0.2 \%, 0.5 \%, 1.0 \%, 1.5 \%$, 2.0\%) of the nanoparticles. Because $\mathrm{Al}_{2} \mathrm{O}_{3}$ nanoparticles have high surface energy, it is easy to cause the reunion phenomenon when nanoparticles are added to the base oil. Therefore, Lauryl sodium sulfate (SDS) with $0.3 \mathrm{wt} \%$, as a surfactant, was added to improve the stability of suspensions.

The nanofluids with different mass concentrations are listed in Table 4. The nanofluids were prepared by dispersing the nanoparticles into cottonseed oil via a two-step method. Sonication was performed for $1 \mathrm{~h}$ by using a numerical control ultrasonic oscillator.The milling parameters in the experiment are listed in Table 5.

Table 3 Properties of $\mathrm{Al}_{2} \mathrm{O}_{3}$ nanoparticles

\begin{tabular}{ll}
\hline Properties & Value \\
\hline Particle shape & $\begin{array}{l}\text { Spher } \\
\text { e }\end{array}$ \\
Purity (\%) & 99.9 \\
Average particle size $(\mathrm{nm})$ & 70 \\
Apparent density $\left(\mathrm{g} / \mathrm{cm}^{3}\right)$ & 0.33 \\
Specific surface area $\left(\mathrm{m}^{2} / \mathrm{g}\right)$ & 30.21 \\
Thermal conductivity $(\mathrm{W} / \mathrm{m} \mathrm{K})$ & 36 \\
\hline
\end{tabular}

Table 4 Experimental design

\begin{tabular}{lll}
\hline Experimen Milling fluid $\quad$ Nanoparticle's & Lubricating \\
\hline
\end{tabular}




\begin{tabular}{llll}
\hline t no. & & concentration (wt \%) & condition \\
\hline 1 & Pure castol oil & 0 & Pure oil MQL \\
2 & $\mathrm{Al}_{2} \mathrm{O}_{3}$ nanofluid & 0.2 & Nanofluid MQL \\
3 & $\mathrm{Al}_{2} \mathrm{O}_{3}$ nanofluid & 0.5 & Nanofluid MQL \\
4 & $\mathrm{Al}_{2} \mathrm{O}_{3}$ nanofluid & 1 & Nanofluid MQL \\
5 & $\mathrm{Al}_{2} \mathrm{O}_{3}$ nanofluid & 1.5 & Nanofluid MQL \\
6 & $\mathrm{Al}_{2} \mathrm{O}_{3}$ nanofluid & 2 & Nanofluid MQL \\
\hline
\end{tabular}

Table 5 Milling parameters

\begin{tabular}{cc}
\hline Milling parameters & Parameter setting \\
\hline Milling way & Plane milling \\
Tool type & Machine-clamped two-tooth end milling cutter \\
Tool diameter $(\mathrm{mm})$ & 20 \\
Spindle speed $(\mathrm{r} / \mathrm{min})$ & 1,200 \\
Feed speed $(\mathrm{mm} / \mathrm{min})$ & 500 \\
Axial depth $(\mathrm{mm})$ & 0.25 \\
Radial depth $(\mathrm{mm})$ & 10 \\
MQL flow rate $(\mathrm{ml} / \mathrm{h})$ & 85 \\
MQL nozzle distance $(\mathrm{mm})$ & 40 \\
MQL nozzle angle $\left({ }^{\circ}\right)$ & 45 \\
MQL gas pressure $(\mathrm{MPa})$ & 0.4 \\
\hline
\end{tabular}

\section{Results and Discussions}

\subsection{Milling Force}

In the process of machining, milling force is one of the most important parameters. Larger milling force can produce higher heat and then arise interface adhesion phenomenon, seriously affecting the workpiece surface quality and the life of the cutter. Therefore, the milling force is of great significance to improve the machining[44]. To facilitate the analysis, milling force is divided into $\mathrm{X}$ milling force $F_{x}, Y$ milling force $F_{y}$ and axial force $F_{z}$. The trend of cutting force under six kinds of different concentrations of nanofluids measured by dynamometer is shown in Fig 3. 

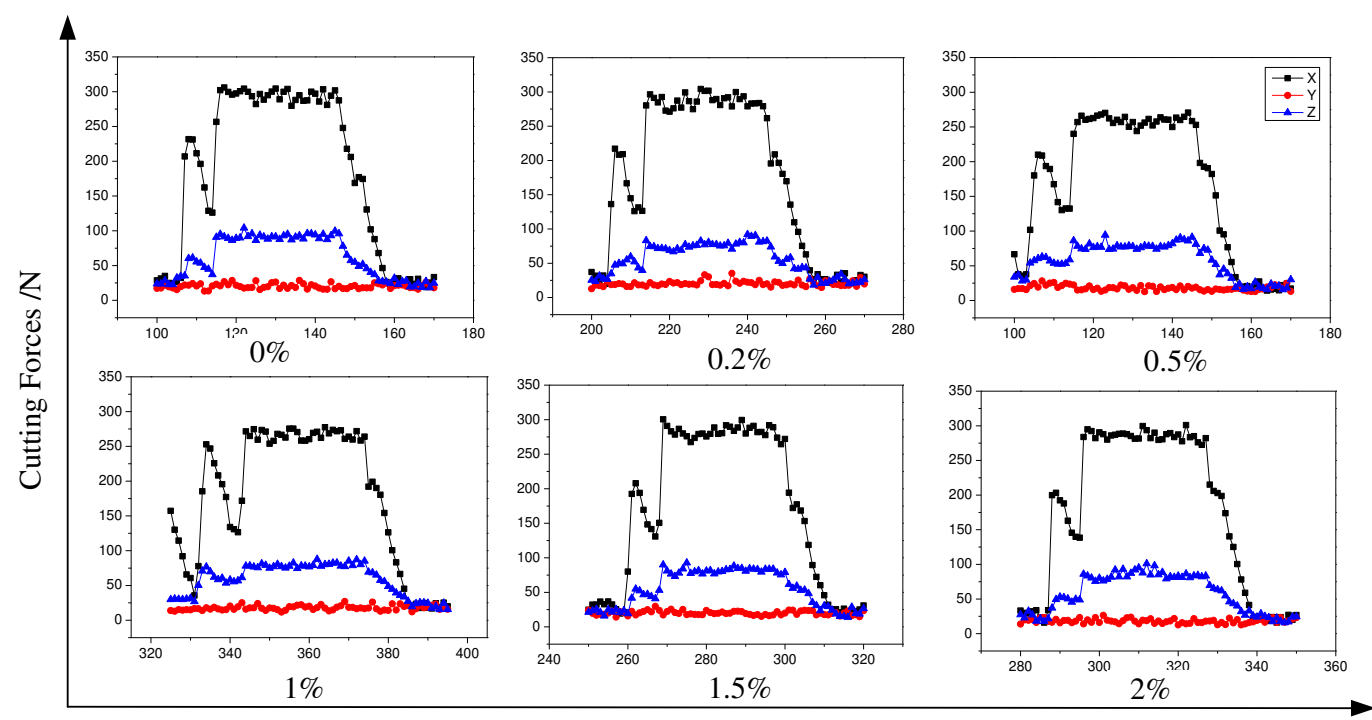

Fig.3 The trend of cutting force under six kinds of different concentrations of nanofluids

\subsection{Specific Cutting Energy}

Specific cutting energy indicates the energy consumed during the machining process, which contains the energy consumed by plastic deformation, friction between the interface of tool/workpiece and the newly formed processing surface[45]. The lower the specific energy is, the higher the processing efficiency is. Thus, the machining processing is environmentally friendly and energy saving. Therefore, it is of significance to controll the specific energy. The specific energy of milling can be calculated by using Eq.1.

$$
U=\frac{P}{Q_{w}}=\frac{F \cdot t}{\alpha_{p} \cdot t \cdot \alpha_{e}}=\frac{F}{\alpha_{p} \cdot \alpha_{e}}
$$

Where $U$ represents the specific energy $\left(J / \mathrm{mm}^{3}\right)$; $\mathrm{P}$, the total energy consumed; $Q_{w}$, the volume of material removed by tool; $\alpha_{p}$ is the radial depth of cut(mm), $\alpha_{e}$ is the axial depth of cut $(\mathrm{mm})$ and $\mathrm{F}$ represents the resultant force $(\mathrm{N})$, which can be calculated according to Eq.2.

$$
F=\sqrt{F_{X}^{2}+F_{Y}^{2}+F_{Z}^{2}}
$$




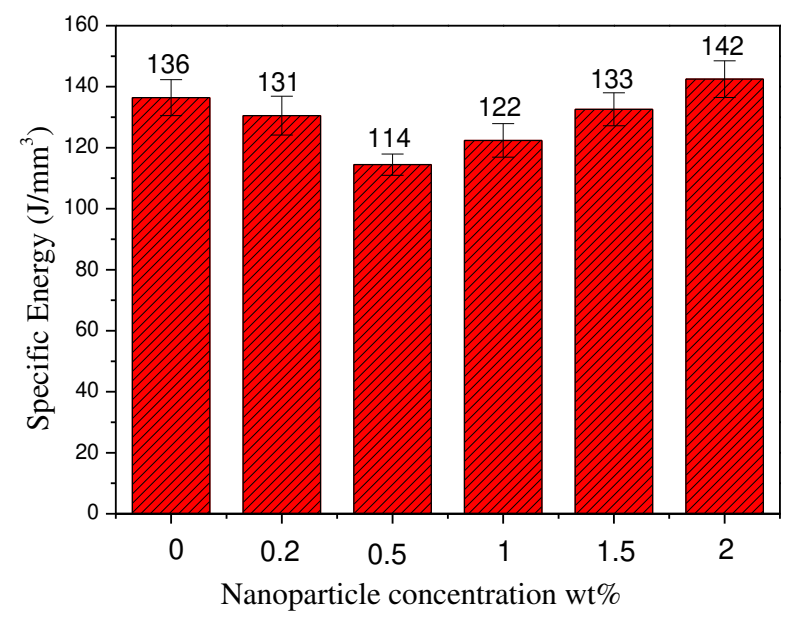

Fig.4 The specific energy obtained using different $\mathrm{Al}_{2} \mathrm{O}_{3}$ concentration

The specific energy obtained using different $\mathrm{Al}_{2} \mathrm{O}_{3}$ concentration (wt\%) is shown in Fig. 4. It is shown that the specific energy gradually decreases with the increase in $\mathrm{Al}_{2} \mathrm{O}_{3}$ concentration. However, after $0.5 \mathrm{wt} \%$, the magnitude of specific cutting energy increases. The lowest specific energy is obtained when the $\mathrm{Al}_{2} \mathrm{O}_{3}$ concentration is $0.5 \mathrm{wt} \%$ with the value of $114 \mathrm{~J} / \mathrm{mm}^{3}$. This result indicates that the slight mixing between $\mathrm{Al}_{2} \mathrm{O}_{3}$ and cottonseed can significantly advance the tribological properties of cottonseed, but too high concentration of nanoparticles is not conducive to improve the tribological properties.

Because the nanoparticles have a good anti-friction and anti-wear effect, they can increase the compressive capacity of oil film to reduce milling force. At the same time, $\mathrm{Al}_{2} \mathrm{O}_{3}$ nanoparticles have high thermal conductivity, which also can reduce the milling force. When added into lubricants, these nanoparticles will infiltrate into pores on the surface of the workpiece, and form the oil film due to the shearing of nanoparticles with each other, which helps to decrease the magnitude of cutting forces as well as energy consumption. However, too much nanoparticles will result in their collision and aggregation in the motion, which leads to reunion[46]. Reunion of the nanoparticles will collide with rough surface of workpiece, and thus affect surface quality and produce higher milling force [47].

\subsection{The surface roughness and surface micromorphology}

Surface roughness and surface morphology are important evaluation indexes. 
The surface roughness can quantitatively determine the machining surface quality, while surface micromorphology can qualitatively evaluated the surface quality. When the workpiece quality can't be judged from the surface micromorphology quantitatively, surface roughness can help to determine it.

Five points were selected to measure the surface roughness of six workpieces machined by nanofluid MQL milling, then six groups of roughness value were obtained. The surface roughness and surface micromorphology under different nanoparticle concentration were shown in Fig.5 and Fig.6.

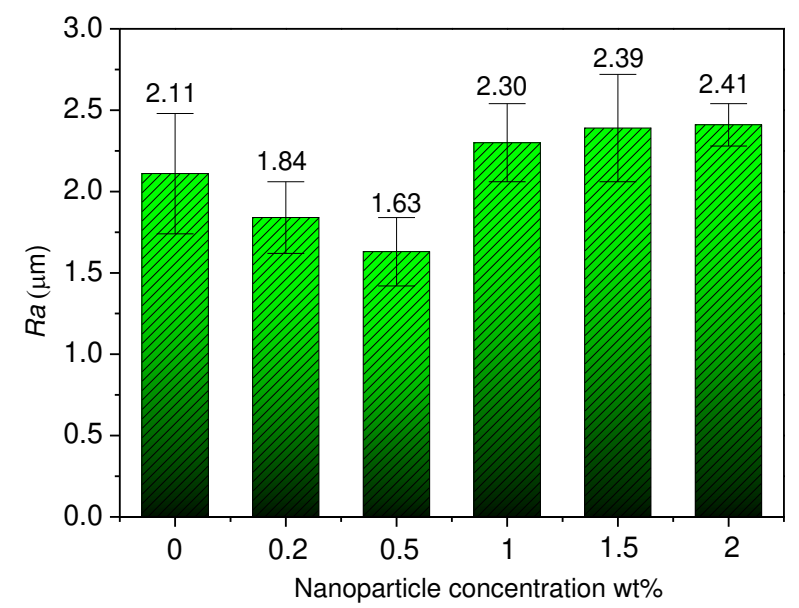

Fig. 5 The surface roughness under different nanoparticle concentration
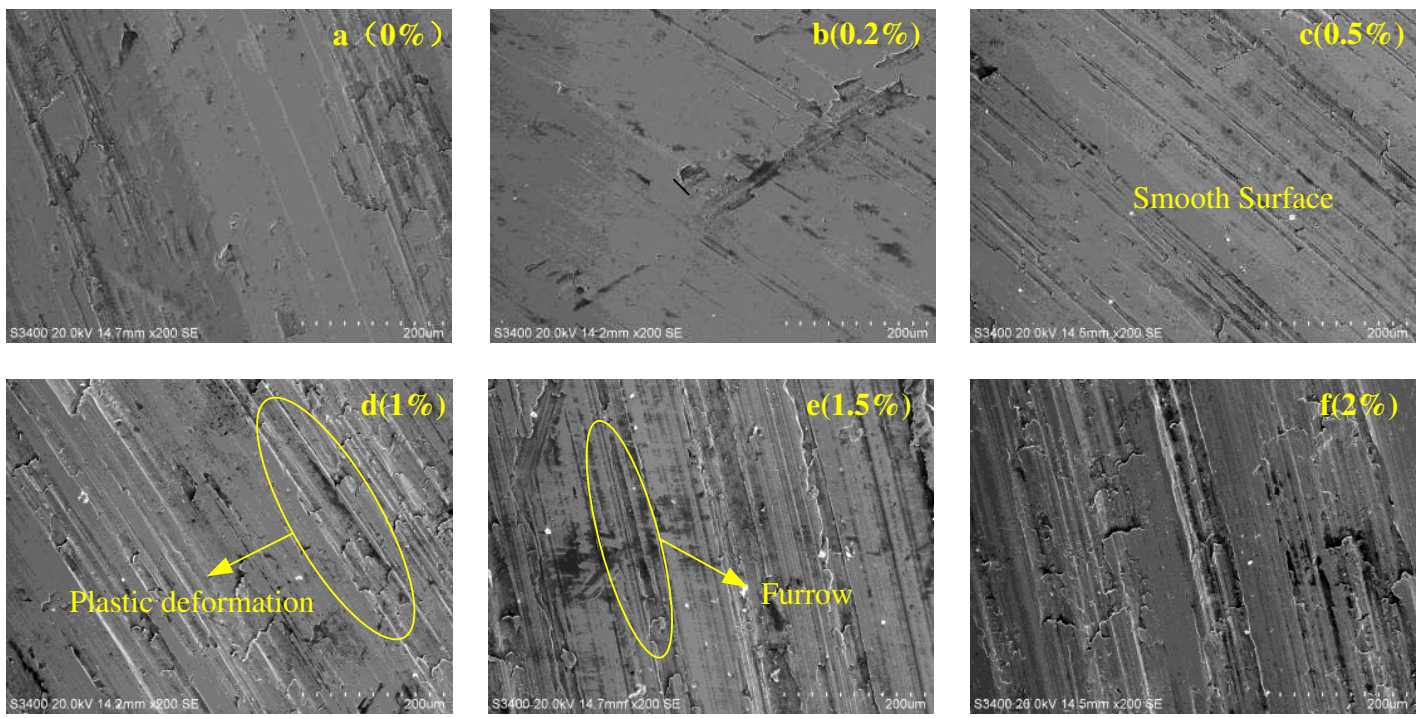

Fig.6 The surface morphology under different nanoparticle concentration

It can be concluded from Fig.5 that the roughness values are different under different nanoparticle concentration . The surface roughness of workpiece under 0.5 
wt\% is the smallest $(R a=1.63 \mu m)$, which is $22.7 \%$ lower than that of pure cottonseed oil. Accordingly, the surface micrmorphology is the best, which means that the best surface quality is obtained under $0.5 \mathrm{wt} \%$ nanoparticle concentration. As the concentration increases from 1 wt\% to 2 wt\%, the surface roughness value becomes larger, and the corresponding surface micromorphology is worse. From Fig.6d-f, it can be observed that there are large furrows and plastic deformation on the workpiece surface, which shows that when the concentration of nanoparticles increases, the surface quality decreases. The reason is that when the concentration of nanoparticles is high, nanoparticles will penetrate into the surface cavity of the workpiece. After that, these particles will be sheared off by the incoming nanoparticles and appear in the oil film, then enhance the wear, which greatly reduces the surface quality of the workpiece.

\subsection{The morphology of chip surface}

Chip formation process is the essence and basis of the change of physical and chemical phenomena in the cutting process, such as cutting force and cutting temperature[48]. Observing the morphology and shape of chip is a simple method to judge the lubrication performance of lubricating fluid[49]. Fig.7 shows the chip morphology collected in MQL milling with different concentration of nanofluids. The contact surface between the chip and the milling cutter is the front chip, and the other side is the rear chip. The front chip is smoother than the back because the rear chip is rippled due to the extrusion in the cutting process. The chip with the concentration of nanoparticles from $0 \mathrm{wt} \%$ to $0.5 \mathrm{wt} \%$ has smooth surface, and it is slender and curly. The chip surface of $0.5 \mathrm{wt} \%$ is the smoothest, and the cracks on both the sides are the slightest and the most uniform, which indicates that the force is the smallest in the milling process. However, as the particle concentration increases from $1 \mathrm{wt} \%$ to $2 \mathrm{wt} \%$, the chips are short and small, and there are obvious cracks on the chip surface, which indicates that high concentrations of nanoparticles are not beneficial to the formation of good surfaces[42]. This is consistent with the micromorphology of the workpiece surface under different concentrations. 

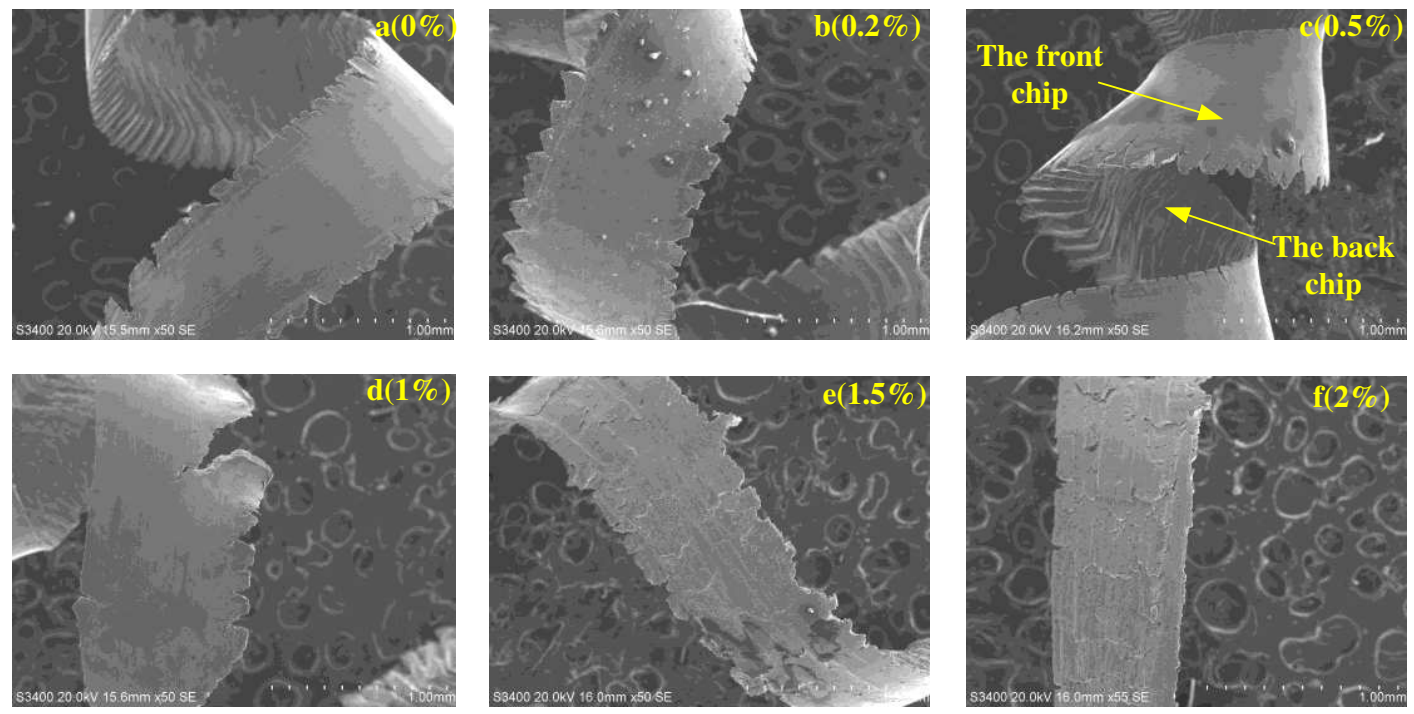

Fig.7 The chip morphology under different nanoparticle concentration

\subsection{Contact angle}

Wettability is used to describe the spreading, penetration, and ability of fluid to cover the tool and workpiece. The smaller the contact angle is, the better the wettability is, and the larger the wettability area of the same volume droplet on the surface is. A larger infiltration area means that the milling fluid can effectively cover more areas, resulting in better lubrication. Fig. 8 shows a schematic diagram about the droplet, the contact angle $\theta$ and the workpiece surface. The smaller $\theta$ is, the larger the infiltration and the lubrication area is. Accordingly, the milling force and surface roughness of workpiece are reduced.

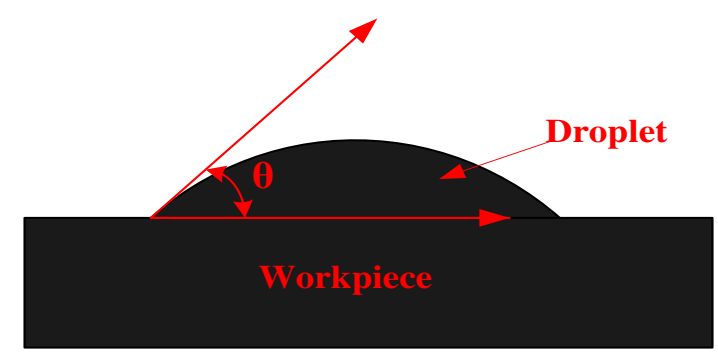

Fig.8 The schematic diagram of contact angle 

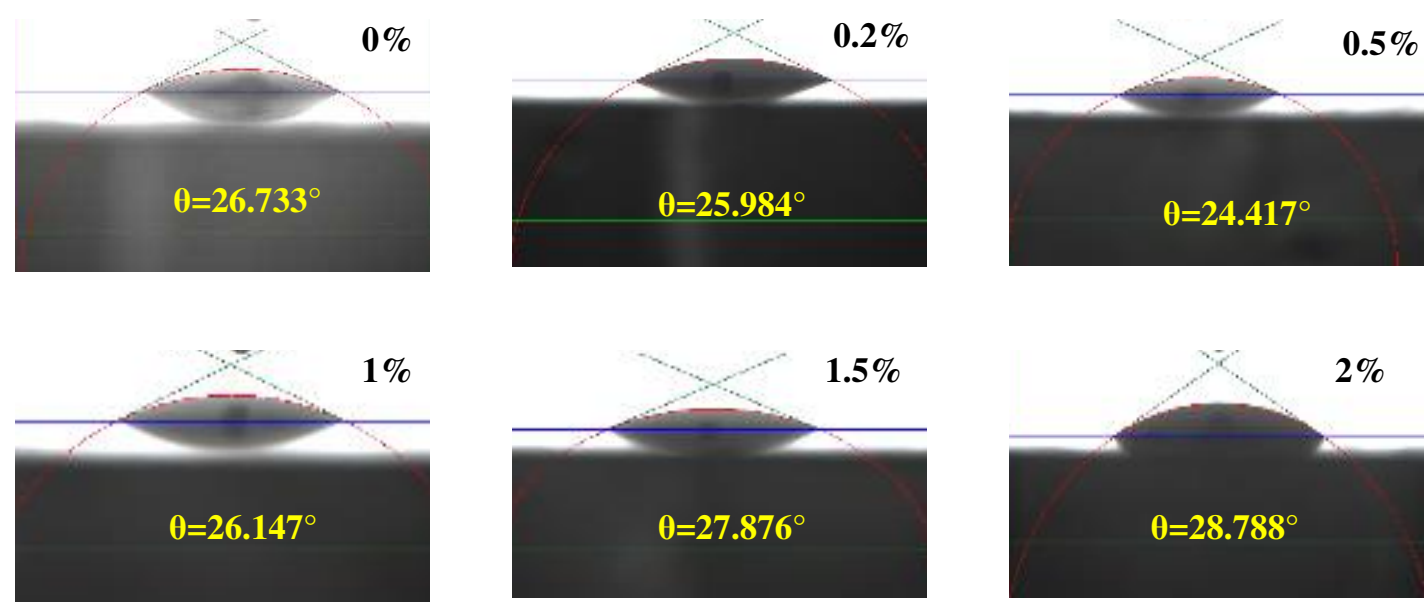

Fig.9 The contact angle under different nanoparticle concentration

Fig.9 shows the contact angle of different concentrations of nanofluids sprayed on the workpiece surface. With the addition of nanoparticles, the contact angle decreases significantly. When the concentration of nanoparticles is $0.5 \mathrm{wt} \%$, the contact angle decreases to the minimum value. After that, the contact angle increases with the increase of the concentration of nanoparticles. The possible reason is that the particle size of spherical $\mathrm{Al}_{2} \mathrm{O}_{3}$ nanoparticle is $70 \mathrm{~nm}$, which is many times larger than that of cottonseed oil. These nanoparticles have larger magnitude than oil molecules in size and density, which will exert additional downward extrusion force to oil molecules towards the contact surface and reduce the contact angle of droplets and increase the wettability. With appropriate amount of nanoparticles being added into the base oil, more particles will participate in this effect, and further reduce the fluid contact angle [50]. Accordingly, the strength of lubricating oil film is improved by adding nanoparticles. However, when the concentration is higher than $0.5 \mathrm{wt} \%$, the contact angle increases, because too many nanoparticles can not be completely dispersed into the base oil, which results in agglomeration, loss of dynamic stability and precipitation. Therefore, the wettability of the fluid is reduced, and the surface quality of workpiece correspondingly decreases as shown in Fig.6d-f.

\subsection{Viscosity}

Viscosity reflects the adhesion among molecules due to irregular motions, which is an important factor affecting its lubrication properties. It is difficult for low 
viscosity to form oil film with sufficient strength and thickness. Therefore, it is necessary to observe the viscosity of nanofluid under different nanoparticle concentration.

As shown in Fig.10, the viscosity of nanofluids increases apparently from 49.4 $\mathrm{mPa}$ 's to $53.6 \mathrm{mPa}$ 's with the increase of nanofluid concentration from 0 to $0.5 \%$. However, when the nanoparticle concentration is above 0.5 wt\%, the viscosity increases moderately. This is likely caused by the agglomeration of nanoparticles of high concentration of nanofluid. Therefore, the viscosity of nanofluid increases slightly after reaching saturation[51]. As a result, the further increase of viscosity is not helpful to improve the lubrication performance of the nanofluids.

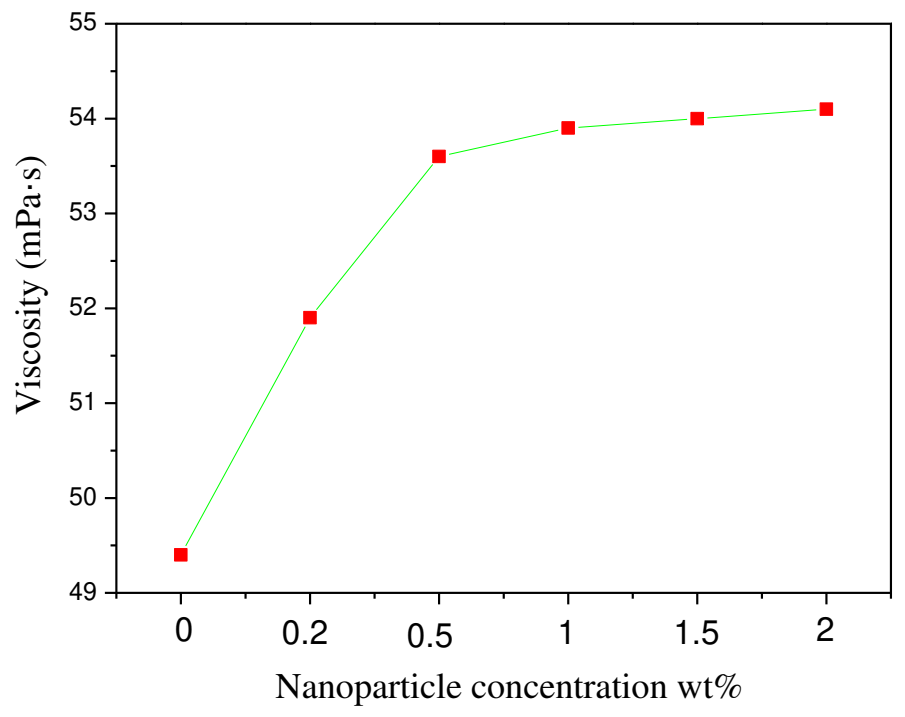

Fig.10 The viscosity under different nanoparticle concentration

\section{Conclusions}

In this study, the nanofluid of different $\mathrm{Al}_{2} \mathrm{O}_{3}$ concentration based on cottonseed has been utilized to determine the milling performance. Milling force, specific energy, surface quality and chip formation were investigated. Furthermore, viscosity and contact angle were analyzed. Based on the experimental findings, it can be concluded:

(1) The specific energy gradually decreases with the increase in $\mathrm{Al}_{2} \mathrm{O}_{3}$ concentration. However, after 0.5 wt\% concentration, the magnitude of specific cutting energy increases again. The lowest specific energy is obtained when the $\mathrm{Al}_{2} \mathrm{O}_{3}$ 
concentration is $0.5 \mathrm{wt} \%$ with the value of $114 \mathrm{~J} / \mathrm{mm}^{3}$. This result indicates that the slight mixing between $\mathrm{Al}_{2} \mathrm{O}_{3}$ and cottonseed can significantly advance the tribological properties of cottonseed, but too high concentration of nanoparticles is not conducive to improve the tribological properties.

(2) When the concentration of nanoparticles is $0.5 \mathrm{wt} \%$, the best tribological properties are obtained. The surface roughness $R a$ is $1.63 \mu m$ and the chips are slender and smooth. When the concentration of nanoparticles further increases, the surface quality of the workpiece becomes worse, and the chip short and the surface rough.

(3) When the concentration of nanoparticles increases larger than $0.5 \mathrm{wt} \%$, nanoparticles agglomerate and the increase of nanofluids viscosity decreases greatly. At the same time, the contact angle of the droplet with the concentration of $0.5 \mathrm{wt} \%$ has a minimum value, representing the maximum wettability area and optimal lubrication performance.

(4) According to the above results, nanofluid has better tribological properties than pure cottonseed oil and can significantly improve the milling performance. When the concentration of nanoparticles is $0.5 \mathrm{wt} \%$, the best tribological properties are obtained.

\section{Ethical Approval}

There was no ethical issue in this project

\section{Consent to Participate}

Not applicable .

\section{Consent to Publish}

All authors have read and agreed to the published version of the manuscript. 


\section{Authors Contributions}

Xiufang Bai: design of experiments, analysing and arranging data, and writing the manuscript; Juan Jiang: design of experiments, and analysing and arranging data; Changhe Li: planning the steps of the research, and reviewing the manuscript; Lan Dong:coordinating the steps of the research, and reviewing the manuscript; Zhenjing Duan:conducting experiments, and collecting and analysing data; Haiying Zhang: conducting experiments.

\section{Funding}

This research was financially supported by the following organizations: the Scientific Research Development Project of Shandong Higher Education Institutions, China (J18KA017 and J17KB016), the National Natural Science Foundation of China (51806112 and 51575290).

\section{Competing Interests}

The authors declare no conflict of interest.

\section{Availability of data and materials}

The datasets generated during the current study are available from the corresponding author on reasonable request.

\section{References}

1. Zhang JC, Li CH, Zhang YB, Yang M, Jia DZ, Hou YL, Li RZ (2018) Temperature field model and experimental verification on cryogenic air nanofluid minimum quantity lubrication grinding. The International Journal of Advanced Manufacturing Technology 97(1-4):209-228.

2. Li HN, Yang Y, Zhao YJ, Zhang ZL, Zhu WQ, Wang WL, Qi H (2019) On the periodicity of fixed-abrasive planetary lapping based on a generic model. Journal of Manufacturing Processes 44:271-287. 
3. Guo SM, Li CH, Zhang YB, Yang M, Jia DZ, Zhang XP, Liu GT, Li RZ, Bing ZR, Ji HZ (2018) Analysis of volume ratio of castor/soybean oil mixture on minimum quantity lubrication grinding performance and microstructure evaluation by fractal dimension. Industrial Crops \& Products 11:494-505.

4. Ekinovic S, Prcanovic H, Begovic E(2015) Investigation of influence of MQL machining parameters on cutting forces during MQL turning of carbon steel St52-3. Rrocescia Engineering $132: 608-614$

5. Khan MMA, Mithu MAH, Dhar NR(2009) Effects of minimum quantity lubrication on turning AISI 9310 alloy steel using vegetable oil-based cutting fluid. Journal of Materials Processing Technology 209:5573-5583.

6. Hamdan A, Sarhan AAD, Hamdi M (2012) An optimization method of the machining parameters in high-speed machining of stainless steel using coated carbide tool for best surface finish. International Journal of Advanced Manufacturing Technology 6-858(1-4):81-91.

7. Mao C, Sun XL, Huang H, Kang CW, Zhang MJ, Wu YQ (2016) Characteristics and removal mechanism in laser cutting of cBNWC-10Co composites. Journal of Materials Processing Technology 230:42-49.

8. Mao C, Zhang MJ, Zhang J, Tang K, Gan HY, Zhang GF (2015) The effect of processing parameters on the performance of spark plasma sintered CBN-WC-Co composites. Journal of Materials Engineering and Performance 24:4612-4619.

9. Boswell B, Islam MN, Davies IJ, Ginting YR, Ong AK (2017) A review identifying the effectiveness of minimum quantity lubrication (MQL) during conventional machining. International Journal of Advanced Manufacturing Technology 92:321-340.

10. Li CH, Li JY, Wang S, Jia DZ (2013) Modeling and numerical simulation of the grinding temperature distribution with nanoparticle jet of MQL. Advanced Mechanical Engineering 7:167-181.

11. Cetin M H, Ozcelik B, Kuram E, Demerbas E(2011) Evaluation of vegetable based cutting fluids with extreme pressure and cutting parameters in turning of AISI 304L by Taguchi method. Journal of Cleaner Production 19(17): 2049-2056. 
12. Said D, Belinato G, Sarmiento GS, Otero RLS, Totten GE, Gastón A, Canale LCF( 2013). Comparison of Oxidation Stability and Quenchant Cooling Curve Performance of Soybean Oil and Palm Oil. Journal of Materials Engineering and Performance 22(7): 1929-1936.

13. Lawal SA, Choudhury IA, Nukman Y(2012) Application of vegetable oil-based metalworking fluids in machining ferrous metals a review. International Journal of Machining Tools \& Manufacturing 52(1):1-12.

14. Kuram E, Ozcelik B, Bayramoglu M, Demirbas E, Simsek T(2013) Optimization of cutting fluids and cutting parameters during end milling by using D-optimal design of experiments. Journal of Cleaner Production 42(3):159-166.

15. Syahrullail S, Kamitani S, Shakirin A(2014) Tribological evaluation of mineral oil and vegetable oil as a lubricant. Jurnal Teknologi 66(3): 37-44.

16. Wang YG, Li CH, Zhang YB, Yang M, Li BK, Jia DZ, Hou YL, Mao C (2016) Experimental evaluation of the lubrication properties of the wheel/workpiece interface in minimum quantity lubrication (MQL) grinding using different types of vegetable oils. Journal of Cleaner Production 127:487-499.

17. Li BK, Li CH, Zhang YB, Wang YG, Jia DZ, Yang M, Zhang NQ, Wu QD, Han ZG, Sun K (2017) Heat transfer performance of MQL grinding with different nanofluids for Ni-based alloys using vegetable oil.Journal of Cleaner Production 154:1-11.

18. Li BK, Ding WF, Yang CY, Li CH (2019) Grindability of powder metallurgy nickel-base superalloy FGH96 and sensibility analysis of machined surface roughness. International Journal of Advanced Manufacturing Technology 101: 2259-2273.

19. Cetin M H, Ozcelik B, Kuram E, Demirbas E(2011) Evaluation of vegetable based cutting fluids with extreme pressure and cutting parameters in turning of AISI 304L by Taguchi method. Journal of Cleaner Production 19:2049-2056.

20. Pervaiz S, Rashid A, Deiab I, Nicolescu CM (2016) An experimental investigation on effect of minimum quantity cooling lubrication(MQCL) in machining titanium alloy (Ti6Al4V). The International Journal of Advanced Manufacturing Technology 87:1371-1386.

21. Bai XF, Zhou FM, Li CH, Dong L, Lv XJ, Yin QA.(2020) Physicochemical Properties of Degradable Vegetable-based Oils on Minimum Quantity Lubrication Milling. International Journal of Advanced Manufacturing Technology.106:4143-4155. 
22. Uysal A, Demiren F, Altan E (2015) Applying minimum quantity lubrication (MQL) method on milling of martensitic stainless steel by using nano MoS2 reinforced vegetable cutting fluid. Procedia-Social and Behavioral Sciences 195: 2742-2747.

23. Ding WF, Zhu YJ, Zhang LC, Xu JH, Fu YC, Liu WD, Yang CY (2015) Stress characteristics and fracture wear of brazed CBN grains in monolayer grinding wheels. Wear 332-333:800-809. 702. 24. Setti D, Sinha MK, Ghosh S, Rao PV. (2015) Performance evaluation of Ti-6Al-4V grinding using chip formation and coefficient of friction under the influence of nanofluids. International Journal of Machine Tools and Manufacture 88:237-248.

25. Zhang YB, Li CH, Jia DZ, Zhang XW(2015) Experimental evaluation of $\mathrm{MoS}_{2}$ nanoparticles in jet MQL grinding with different types of vegetable oil as base oil. Journal of Cleaner Production 87: 930-940.

26. Zhang, YB, Li, CH, Yang, M, Jia DZ, Wang YG, Li BK, Hou YL, Zhang NQ, Wu QD(2016). Experimental evaluation of cooling performance by friction coefficient and specific friction energy in nanofluid minimum quantity lubrication grinding with different types of vegetable oil. Journal of Cleaner Production. 139: 685-705.

27. Luo T, Wei $X$, Huang $X$, Huang L, Yang $F(2014)$ Tribological properties of $\mathrm{Al}_{2} \mathrm{O}_{3}$ nanoparticles as lubricating oil additives. Ceramics International 40(5): 7143-7149.

28. Setti D, Sinha MK, Ghosh S, Rao PV(2015) Performance evaluation of Ti-6Al-4V grinding using chip formation and coefficient of friction under the influence of nanofluids. International Journal of Machine Tools and Manufacture 88: 237-248.

29. Mao C, Tang XJ, Zou HF, Huang XM, Zhou ZX(2012) Investigation of grinding characteristic using nanofluid minimum quantity lubrication. International Journal of Precision Engineering and Manufacturing 13(10): 1745-1752.

30. Li M, Yu TB, Zhang RC, Yang L, Li HY, Wang WS (2018) MQL milling of TC4 alloy by dispersing graphene into vegetable oil based cutting fluid. International Journal of Advanced Manufacturing Technology 99:1735-1753.

31. Hadi M, Atefi $\mathrm{R}$ (2015) Effect of minimum quantity lubrication with gamma- $\mathrm{Al}_{2} \mathrm{O}_{3}$ nanoparticles on surface roughness in milling AISI D3 steel. Indian Journal of Science and Technology 8:296-300. 
32. Bai XF, Li CH, Dong L, Yin QA(2018)Experimental evaluation of the lubrication performances of different anofluids for minimum quantity lubrication (MQL) in milling Ti-6AI-4V. International Journal of Advanced Manufacturing Technology 101:2621-2632.

33. Dong L, Li CH, Bai XF, Zhai MG, Qi Q, Yin QA, Lv XJ, Li LF (2019) Analysis of the cooling performance of Ti-6Al-4 V in minimum quantity lubricant milling with different nanoparticles. International Journal of Advanced Manufacturing Technology 103:2197-2206.

34. Yin QA, Li CH,Zhang YB,Yang M,Jia DZ, Hou YL,Li RZ, Dong L (2018) Spectral analysis and power spectral density evaluation in Al 2 O 3 nanofluid minimum quantity lubrication milling of 45 steel. International Journal of Advanced Manufacturing Technology 97:129-145.

35. Gao $\quad \mathrm{T}$,Li $\quad \mathrm{CH}$,Zhang $\quad \mathrm{YB}$,Yang $\quad \mathrm{M}$,Jia $\quad \mathrm{DZ}$,Tan J,Hou $\quad \mathrm{YL}$,Li $\quad \mathrm{RZ}(2019)$ Dispersing mechanism and tribological performance of vegetable oil-based CNT nanofluids with d ifferent surfactants. Tribology International 131:51-63.

36. Duan, Z.J., Li, C.H., Zhang, Y.B., Dong, L., Bai, X.F., Yang, M., Jia, D.Z., Li, R.Z., Cao, H.J., Xu, X.F. (2020) Milling surface roughness for 7050 aluminum alloy cavity influenced by nozzle position of nanofluid minimum quantity lubrication. Chin J Aeronaut, 1-21.

37. Wang XM , Li CH, Zhang YB , Ding WF, Yang M, Gao T, Cao HJ , Xu XF ,Wang DZ, Said Z, Debnath S, Jamil M , Ali

HM(2020)Vegetable oil-based nanofluid minimum quantity lubrication turning: Academic review and perspectives.Journal of Manufacturing Processes 59: 76-97.

38. Gao T,Li CH,Jia DZ,Zhang YB,Yang M,Wang XM,Cao HJ,Li RZ,Ali HM ,Xu XF(2020) Surface morphology assessment of CFRP transverse grinding using CNT nanofluid minimum quant ity lubrication. Journal of Cleaner Production 277:123328.

39. Zhang DK, Li CH, Jia DZ, Zhang YB, Zhang XP (2015) Specific grinding energy and surface roughness of nanoparticle jet minimum quantity lubrication in grinding. Chinese Journal of Aeronaut 28:570-581.

40. Zhang XP, Li CH, Zhang YB, Jia DZ, Li BK, Wang YG, Yang M, Hou YL, Zhang XW (2016) Performances of $\mathrm{Al} 2 \mathrm{O} / \mathrm{SiC}$ hybrid nanofluids in minimum-quantity lubrication grinding. International Journal of Advanced Manufacturing Technology 86(1-15):3427-3441.

41. Wang YG, Li CH, Zhang YB, Yang M, Zhang XP, Zhang NQ, Dai JJ (2016) Experimental evaluation on tribological performance of the wheel/workpiece interface in minimum quantity lubrication 
grinding with different concentrations of $\mathrm{Al}_{2} \mathrm{O}_{3}$ nanofluids. Journal of Cleaner Production 142:3571-3583.

42. Rahmati B,Sarhan A A D., Sayuti M. Morphology of surface generated by end milling AL6061-T6 using molybdenum disulfifide (MoS2) nanolubrication in end milling machining .2014.Journal of Cleaner Production. 66 (2014) 685-691.

43. Zhang YB, Li CH, Jia DZ, Li BK, Wang YG,Yang M, Hou YL,Zhang XW(2016) Experimental study on the effect of nanoparticle concentration on the lubricating property of nanofluids for MQL grinding of Ni-based alloy[J]. Journal of Materials Processing Technology 232: 100-115.

44. Hwang YK, Lee CM, Park SH (2009) Evaluation of machinability according to the changes in machine tools and cooling lubrication environments and optimization of cutting conditions using Taguchi method. International Journal of Precision Engineering and Manufacturing 10(3):65-73.

45. Sen B, Mia M, Gupta MK, Rahman MA, Mandal UK, Mondal SP (2019) Influence of $\mathrm{Al}_{2} \mathrm{O}_{3}$ and palm oil-mixed nano-fluid on machining performances of inconel-690: if-then rules-based fis model in eco-benign milling. The International Journal of Advanced Manufacturing Technology 103:9-12.

46. Zhang YB, Li CH, Jia DZ, Zhang DK, Zhang XW(2015)Experimental evaluation of MoS2 nanoparticles in jet MQL grinding with different types of vegetable oil as base oil. Journal of Cleaner Production 87(1):930-940.

47. Salyut M, Sarhan A A D, Hamdi M(2013) An investigation of optimum SiO2 nanolubrication parameters in end milling of aerospace Al6061-T6 alloy. The International Journal of Advanced Manufacturing Technology67(1-4): 833-849.

48. Xu DC, Feng PF, Li WB, Ma Y, Liu B (2014) Research on chip formation parameters of aluminum alloy 6061-T6 734 based on high-speed orthogonal cutting model. The International Journal of Advanced Manufacturing Technology 735 72(5-8): 955-962.

49. Sun J, Guo YB. (2008) A new multi-view approach to characterize 3D chip morphology and properties in end milling titanium Ti-6Al-4V. International Journal of Machine Tools and Manufacture 48(12-13): 1486-1494.

50. Chinnam J, Das D, Vajjha R(2015). Measurements of the contact angle of nanofluids and development of a new correlation. International Communications in Heat and Mass Transfer 62: 1-12. 
51. Demas NG, Timofeeva EV, Routbort JL, Fenske GR (2012) Tribological Effects of BN and MoS2 Nanoparticles Added to Polyalphaolefin Oil in Piston Skirt/Cylinder Liner Tests. Tribology Letters 47(1):91-102. 


\section{Figures}
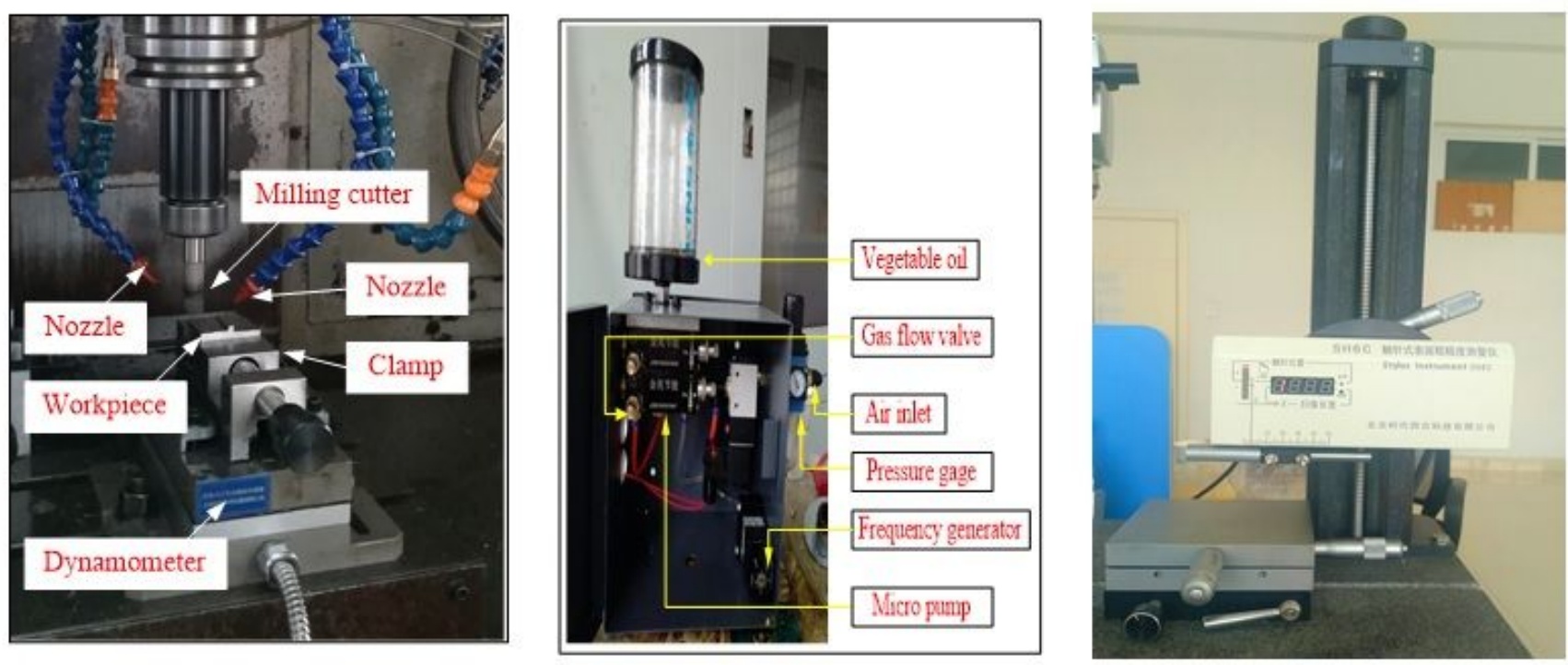

(a)Milling force measuring device

(b)MQL supply system

(c)Surface roughness instrument
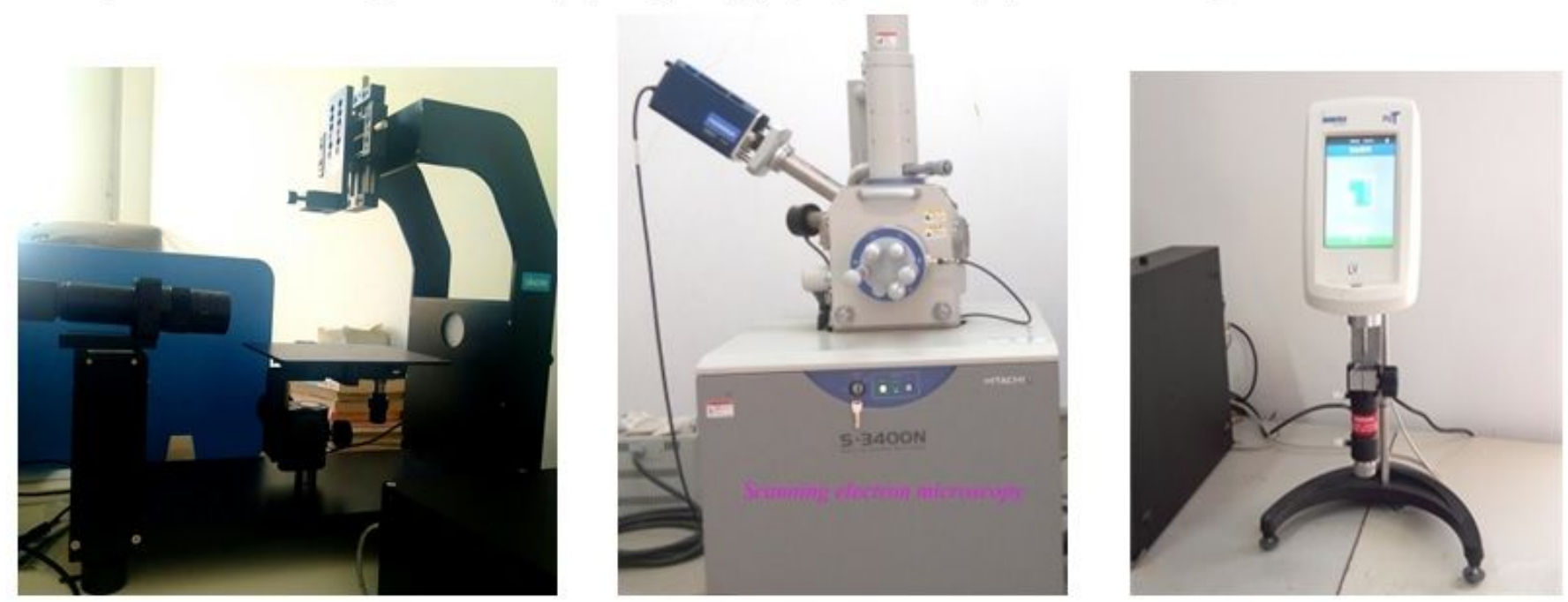

(d) contact angle instrument

(e) Scanning electron microscope(SEM) (f) Viscometer

Figure 1

Experiment instruments 


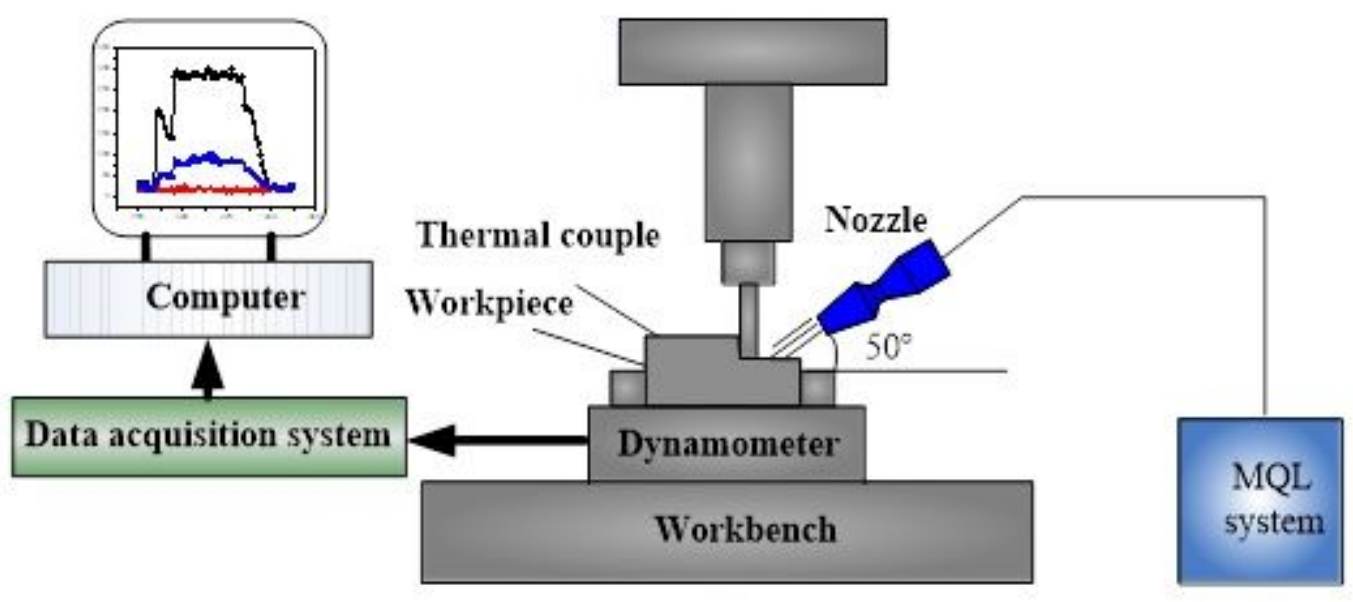

Figure 2

Schematic of milling experiment

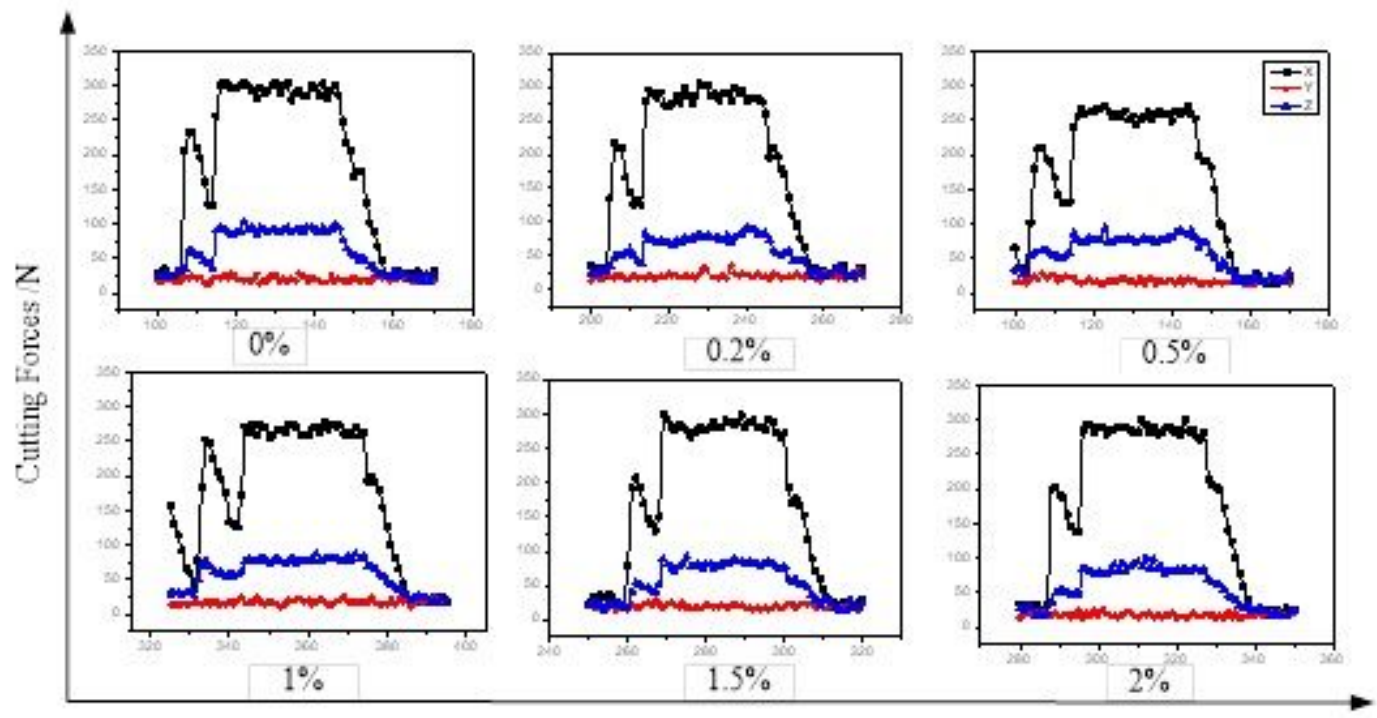

Figure 3

The trend of cutting force under six kinds of different concentrations of nanofluids 


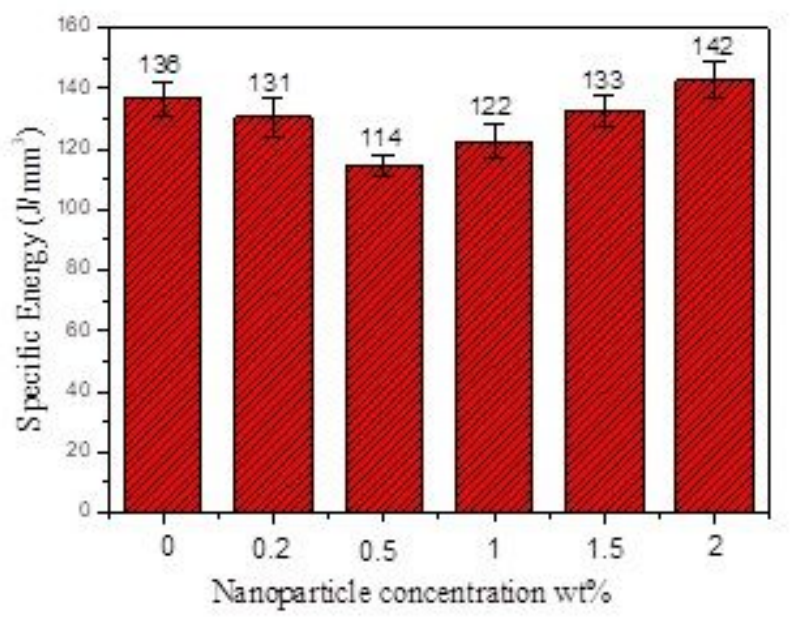

Figure 4

The specific energy obtained using different Al2O3 concentration

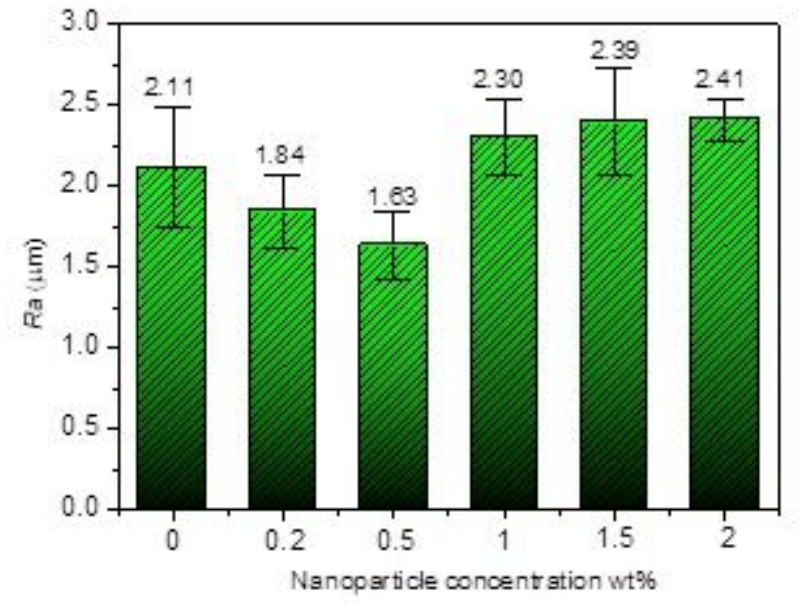

Figure 5

The surface roughness under different nanoparticle concentration 

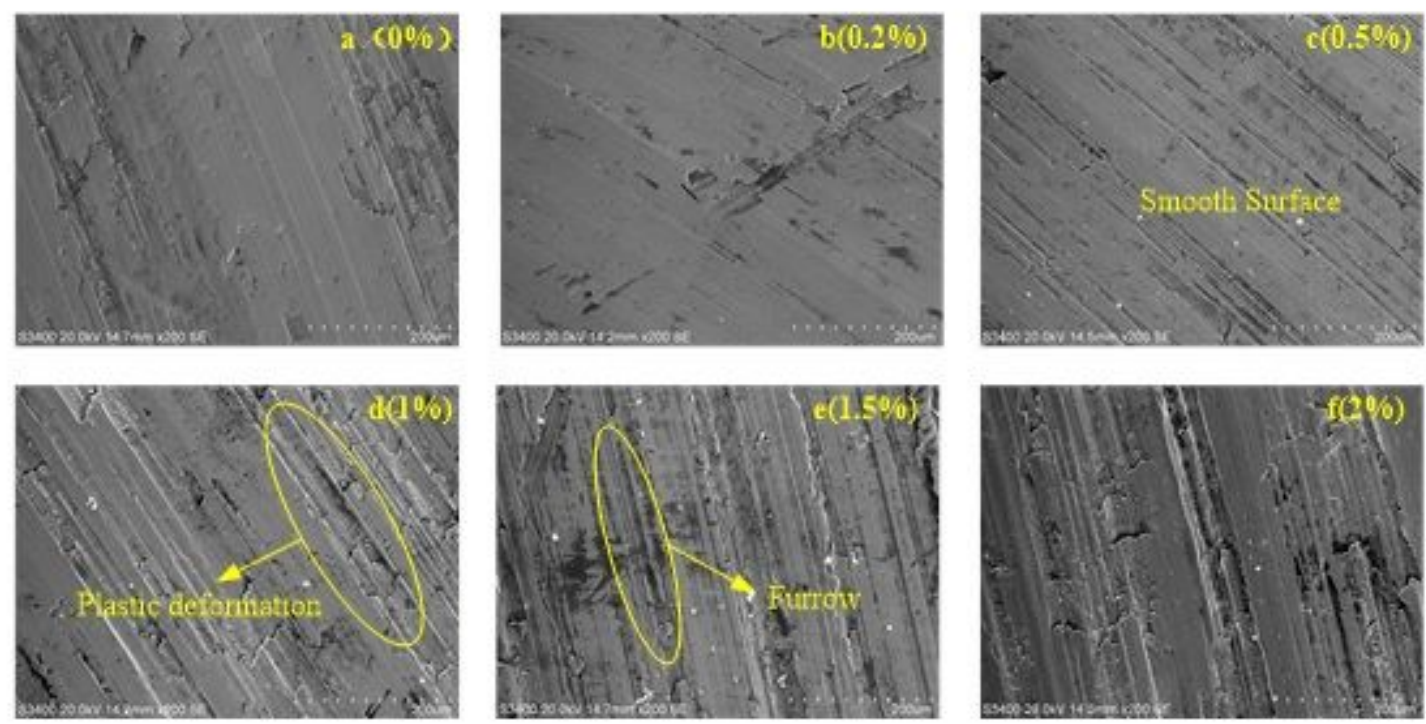

\section{Figure 6}

The surface morphology under different nanoparticle concentration
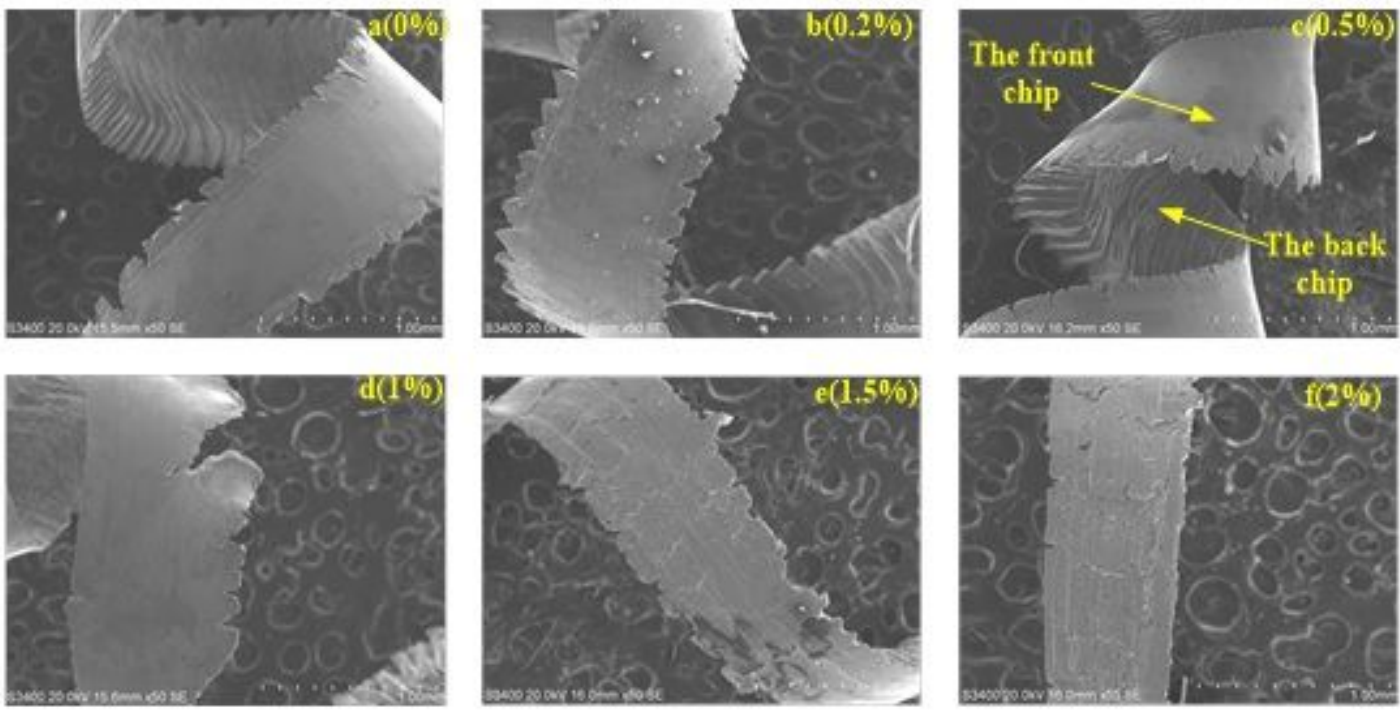

Figure 7

The chip morphology under different nanoparticle concentration 


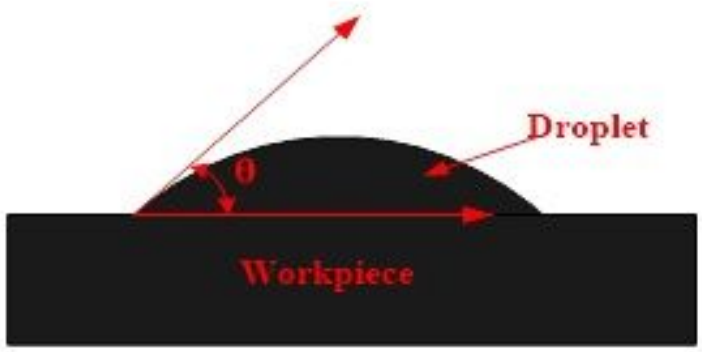

Figure 8

The schematic diagram of contact angle
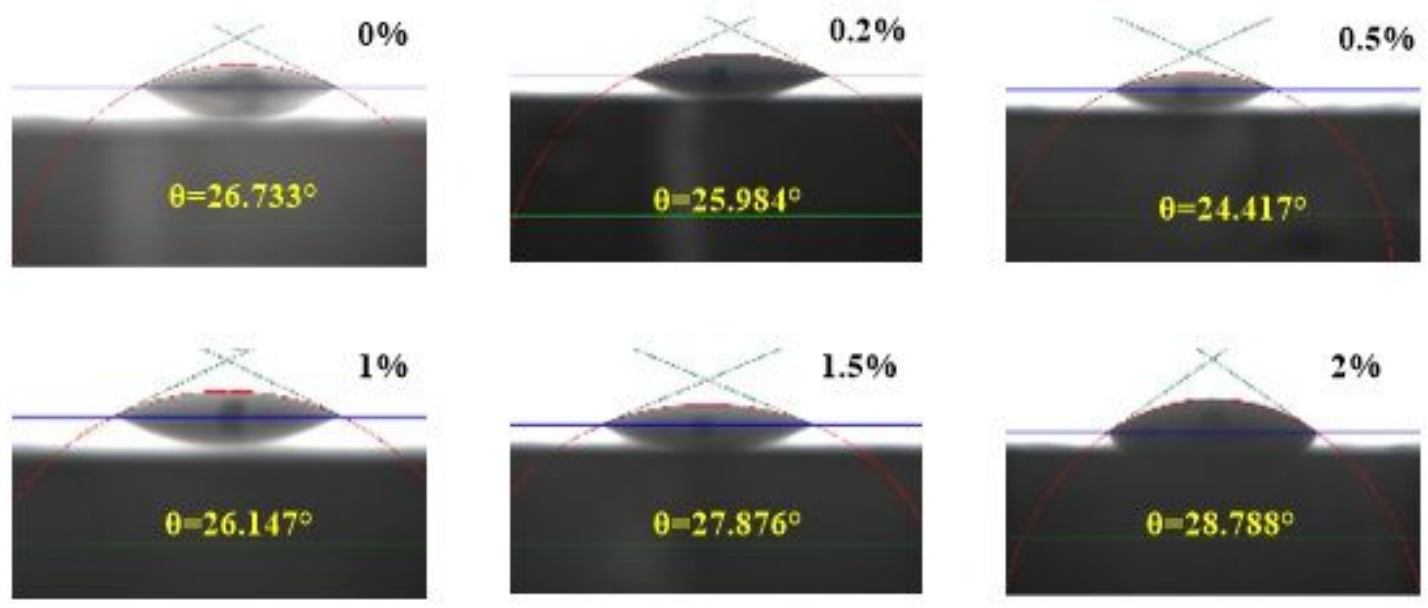

Figure 9

The contact angle under different nanoparticle concentration 


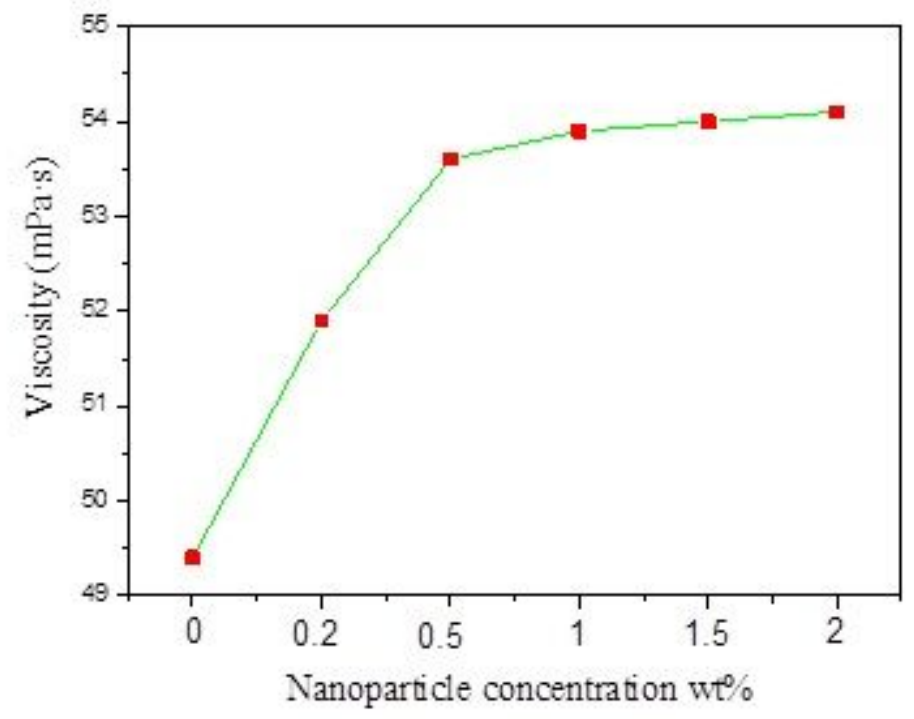

Figure 10

The viscosity under different nanoparticle concentration 